\title{
Influence of the austenitic stainless steel microstructure on the void swelling under ion irradiation
}

\author{
Baptiste Rouxel $^{1, *}$, Caroline Bisor ${ }^{2}$, Yann De Carlan ${ }^{1}$, Arnaud Courcelle $^{2}$, and Alexandre Legris ${ }^{3}$ \\ ${ }^{1}$ DEN-Service de Recherches Métallurgiques Appliquées, CEA, Université Paris-Saclay, 91191 Gif-sur-Yvette, France \\ ${ }^{2}$ DEN-Service d'Études des Matériaux Irradiés, CEA, Université Paris-Saclay, 91191 Gif-sur-Yvette, France \\ ${ }^{3}$ Unité Matériaux et Transformations (UMET), UMR CNRS 8207, Université Lille 1, 59655 Villeneuve d'Ascq, France
}

Received: 8 July 2015 / Received in final form: 16 November 2015 / Accepted: 20 May 2016

\begin{abstract}
To understand the role of different metallurgical parameters on the void formation mechanisms, various austenitic stainless steels were elaborated and irradiated with heavy ions. Two alloys, in several metallurgical conditions $(15 \mathrm{Cr} / 15 \mathrm{Ni}-\mathrm{Ti}$ and $15 \mathrm{Cr} / 25 \mathrm{Ni}-\mathrm{Ti})$, were irradiated in the JANNUS-Saclay facility at $600{ }^{\circ} \mathrm{C}$ with $2 \mathrm{MeV} \mathrm{Fe}^{2+}$ ions up to $150 \mathrm{dpa}$. Resulting microstructures were observed by Transmission Electron Microscopy (TEM). Different effects on void swelling are highlighted. Only the pre-aged samples, which were consequently solute and especially titanium depleted, show cavities. The nickel-enriched matrix shows more voids with a smaller size. Finally, the presence of nano-precipitates combined with a dense dislocation network decreases strongly the number of cavities.
\end{abstract}

\section{Introduction}

In the framework of the GEN IV Sodium Fast Reactors (SFR) program, CEA is developing new austenitic steels for fuel-pin claddings. These steels have been selected because they exhibit the required properties: good formability, weldability, compatibility with sodium, good corrosion resistance and very good mechanical properties at service $\left(400-700{ }^{\circ} \mathrm{C}\right)$.

However, austenitic steels are limited in dose (dpa) because they swell under irradiation. This behaviour causes dimensional changes of fuel assemblies which have consequently to be regularly replaced. Swelling is the consequence of voids formation by vacancies supersaturation induced by irradiation. Cavities as a new type of radiation defect were discovered in 1967 by Cawthorne and Fulton in the Dounreay Fast Reactor [1]. Since then, a lot of research has been done to better understand this phenomenon and to reduce the swelling under irradiation [2,3]. Currently in France, the most optimized steel is a $15 \mathrm{Cr}-15 \mathrm{Ni}$ (named AIM1), stabilized with titanium and cold worked $(\mathrm{CW})$. This is the reference material for the first core of the future CEA SFR reactor, called ASTRID. This alloy should be able to sustain doses up to 100-110 displacements per atom (dpaNRT). New austenitic alloys could be designed to reach higher doses, 120-130 dpa.

\footnotetext{
* e-mail: baptiste.rouxel@cea.fr
}

Swelling under irradiation depends on various microstructural parameters such as the dislocation density [4-7], precipitates [7-10] and the chemical elements in solid solution [8,11-15]. Besides, the role of each of them can be direct or indirect [16]. It has been noticed for a long time that the high dislocation density found in cold-worked steels reduces the swelling. Dislocations trap vacancies and decrease their supersaturation. Nevertheless, a recovering of the dislocation network is observed at high temperature $\left(T>540{ }^{\circ} \mathrm{C}\right)$ and reactivates the swelling. Titanium has been added in the alloys to avoid this phenomenon [5]. It induces the precipitation of nanosized titanium carbides which pin the dislocation network and stabilize it at high temperature. Delalande [17] showed that $15 \mathrm{Cr}-15 \mathrm{Ni}-\mathrm{Ti}$ steel could be stable up to $750{ }^{\circ} \mathrm{C}$. Used with this purpose, titanium plays an indirect role on swelling. Moreover it has been put forward that titanium could have also a direct effect in solid solution $[7,12,14]$.

The objective of this work is to understand better the role of these important metallurgical parameters on the voids formation mechanisms and thus contribute to the development of new austenitic alloys. Ten new alloys were elaborated in OCAS Gent with microstructure similar to that of AIM1. Each alloy has a single composition variation in titanium, phosphorus, silicon, nickel or niobium compared to AIM1. In order to isolate the different microstructural contributions on the swelling mechanisms, each grade is available with various metallurgical states which are described later. To simulate partially the neutron irradiation, some samples have been 


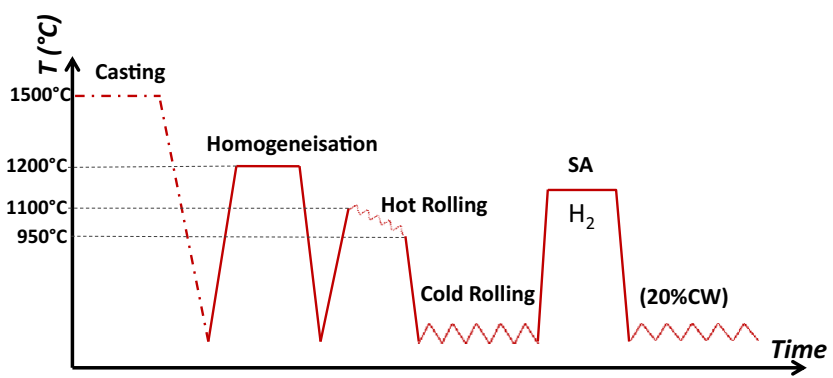

Fig. 1. Diagram of fabrication process.

Table 1. Major constituents of L50 and L47 measured by ICP-OES.

\begin{tabular}{llllllll}
\hline Grade & $\mathrm{Fe}$ & $\mathrm{C}^{\mathrm{a}}$ & $\mathrm{N}^{\mathrm{a}}$ & $\mathrm{Cr}$ & $\mathrm{Ni}$ & $\mathrm{Ti}$ & $\mathrm{Mo}$ \\
\hline L50 & Bal. & 950 & 49 & 14.3 & 16 & 0.42 & 1.5 \\
L47 & Bal. & 900 & 34 & 14.4 & 25.1 & 0.42 & 1.5 \\
\hline
\end{tabular}

Units in weight percent.

${ }^{a}$ Units in ppm.

irradiated with heavy ions in the JANNUS facility at CEA Saclay. TEM observations were also carried out on these samples.

This article discusses the results observed on two steel grades: a $15 \mathrm{Cr}-15 \mathrm{Ni}$ alloy which has the same composition as the industrial AIM1 steel and a $15 \mathrm{Cr}-25 \mathrm{Ni}$ alloy with a higher chemical content in nickel. Both are stabilized with the same amounts of titanium.

\section{Samples description}

\subsection{Elaboration}

The reference material AIM1 is fabricated industrially in the form of tubes $0.5 \mathrm{~mm}$ thick. The experimental materials L50 and L47 made by OCAS and described in this study are model steels produced in small quantities: around $100 \mathrm{~kg}$. They were not shaped by extrusion. They were elaborated as sheets of $0.5 \mathrm{~mm}$ thick by rolling processes detailed below. The fabrication process is given in Figure 1. This metallurgical path is performed to obtain a microstructure close to one of the AIM1.

After casting, the composition of the ingots was measured by Inductively Coupled Plasma Optical Emission Spectrometry (ICP-OES). The results concerning the major constituents are presented in Table 1. L50 (15/15$\mathrm{Ti}$ ) has the same chemical composition as the industrial AIM1 and the only difference with L47 $(15 / 25$ - $\mathrm{Ti})$ is a higher $\mathrm{Ni} / \mathrm{Fe}$ ratio. They contain other minor constituents such as phosphorus and silicon.

Plates of $20 \mathrm{~mm}$ thickness were cut from ingots and homogenised at $1200{ }^{\circ} \mathrm{C}$ during $2 \mathrm{~h}$ in order to dissolve the carbo-nitrides. Then, 7 hot rolling passes were carried out between $1100{ }^{\circ} \mathrm{C}$ and $900{ }^{\circ} \mathrm{C}$ to produce sheets. Finally based on literature [18], various cold working and solution annealing (SA) were tested on each alloy to obtain a final

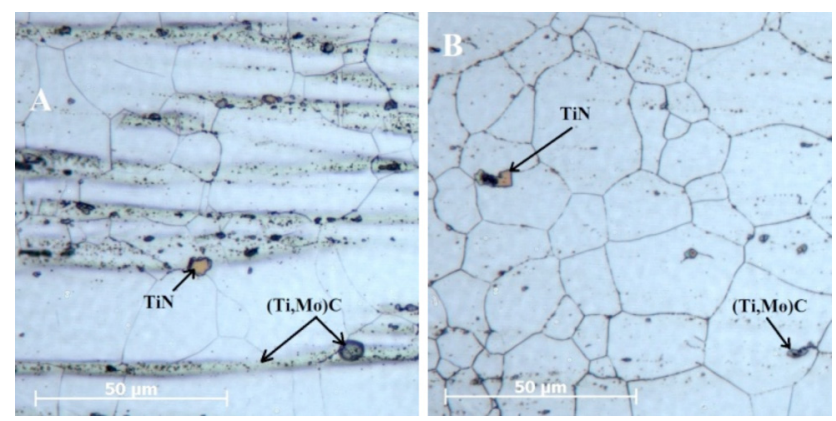

Fig. 2. (A) L50 SA and (B) L47 SA etched with oxalic acid and observed with optical microscope, perpendicular to the rolling direction.

Table 2. Coarse precipitates composition (WDS).

\begin{tabular}{llrrrll}
\hline Grade & Precipitate & \multicolumn{1}{c}{$\mathrm{C}$} & \multicolumn{1}{c}{$\mathrm{N}$} & $\mathrm{Ti}$ & $\mathrm{Mo}$ & $\mathrm{Cr}$ \\
\hline L50 & TiN & 7 & 43 & 49 & 0.03 & 0.44 \\
& $(\mathrm{Ti}, \mathrm{Mo}) \mathrm{C}$ & 43 & 6 & 43 & 7 & 1.5 \\
\hline
\end{tabular}

Units in atomic percent.

grain size between $20 \mu \mathrm{m}$ and $60 \mu \mathrm{m}$. The chosen option is a $80 \%$ cold reduction for $\mathrm{L} 50,70 \%$ for L47, both followed by a SA above $1100{ }^{\circ} \mathrm{C}$ during 2 min. The resulting microstructures observed with an optical microscope are shown in Figure 2.

The measured grain size was $30 \pm 5 \mu \mathrm{m}$ on L50 and $25 \pm 5 \mu \mathrm{m}$ on L47 using the Visilog software. It is less homogeneous in L47. It could be due to complex recrystallization mechanisms known to depend on the stacking fault energy (SFE). SFE is higher in L47 than in L50 because it increases with the Ni content $[19,20]$. In general, a higher SFE makes twins formation more difficult and dislocation cross slip easier, resulting in more dislocation mobility. This will favour more dislocation cells and tend to result in a less homogeneous microstructure [18].

Coarse TiN appear in yellow with a cubic shape and $(\mathrm{Ti}, \mathrm{Mo})(\mathrm{C}, \mathrm{N})$ appear greyish. Both have a diameter of a few micrometers. Precipitates with lower size of 50-200 nm were identified as (Ti, Mo) $(\mathrm{C}, \mathrm{N})$ by Energy Dispersive X-ray spectrometry EDX on carbon replicas. The efficiency of the solution annealing (SA) is probably different compared to the one of an industrial treatment on tubes. Nevertheless, Small-Angle Neutron Scattering (SANS) and fine TEM analysis confirmed the total dissolution of nano-precipitates during the SA.

Microstructures show some heterogeneity in the precipitation, especially in L50. These heterogeneities are already visible after hot rolling. Microprobe analyses show segregations of all addition elements in the zones with the highest concentration of precipitates. The $1200{ }^{\circ} \mathrm{C}$ homogenisation treatment was probably not effective to fully homogenise the material.

The chemical composition of the coarse precipitates was measured with microprobe (WDS). The results given in Table 2 are consistent with literature [10,18]. The result on $\mathrm{C}$ content is indicative. A strong contamination during the 


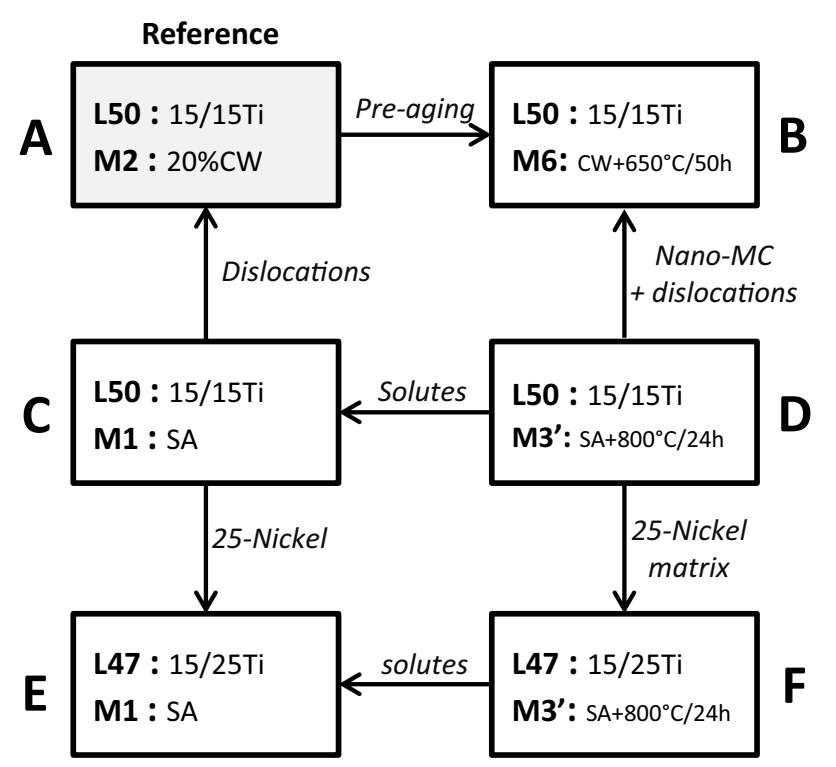

Fig. 3. Schematics of the sample names and the associated thermomechanical treatments. Arrows indicate the investigated effects.

analysis is observed. The presence of nitrogen in $(\mathrm{Ti}, \mathrm{Mo})(\mathrm{C}$, $\mathrm{N})$ limits probably the dissolution of those carbonitrides during the heat treatments.

The remaining amount of $\mathrm{Ti}$ in solid solution is of major importance for the swelling resistance. Assuming that after SA there is no nano-precipitates, the titanium content in solid solution was estimated by WDS on areas without precipitates. L50 SA and L47 SA contain about $0.2 \pm 0.02$ wt. $\%$ of titanium in solid solution.

\subsection{Metallurgical states}

In order to isolate the contribution of different effects on swelling, several metallurgical states were elaborated for the two alloys: M1, M2, M3' and M6 for L50 (15/15-Ti) and only M1 and M3' for L47 (15/25-Ti). A diagram showing the different metallurgical conditions of these 6 samples (places $\mathrm{A}-\mathrm{F}$ ) is presented in Figure 3 and the conclusions which can be made comparing the behaviour of two samples are represented by the arrows. The microstructure of the corresponding samples observed with TEM is given in Figure 5. The TEM micrographs are arranged in the same way than in Figure 3. Finally, the final steps of the fabrication process for the different metallurgical states are given in Figure 4.

The metallurgical cold-worked (CW) state M2 done on L50 is equivalent to the final step of commercial AIM1 fabrication. The fabrication process ends with a $20 \% \mathrm{CW}$ after the SA. It provides a dense dislocation network observable in Figure 5A. Dislocation density has not been measured but the work of Voronin on similar material shows that it could reach $5 \times 10^{14} \mathrm{~m}^{-2}[21]$. The evidence of these high deformed microstructures is the presence of cells (between $100 \mathrm{~nm}$ and $300 \mathrm{~nm}$ ) and mechanical twins. The primary titanium carbides are present only in some regions as noticed from the optical observations. Due to the

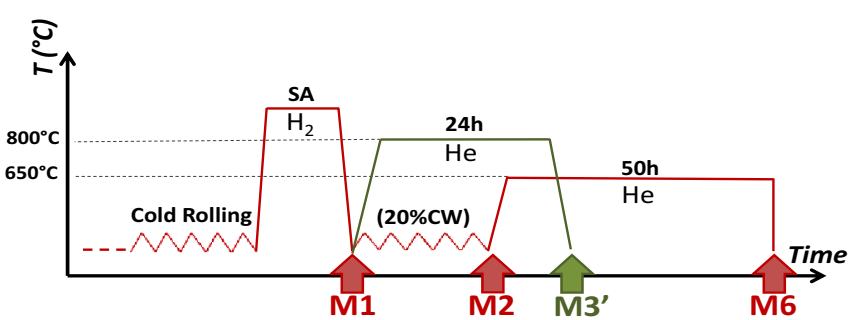

Fig. 4. Final steps of the fabrication process for the different metallurgical states.

competition of all direct and indirect contributions of dislocations, precipitates and solutes on swelling, conclusions on mechanisms are difficult to reach. To isolate and differentiate the effect of the dislocations, the solutes and the precipitates, other specific metallurgical states were elaborated.

M1 (or SA) samples (C and E in Figs. 3 and 5) did not undergo the final $20 \% \mathrm{CW}$. The final step consists in a 2 min SA to keep as much as possible the solutes in solid solution and provides a low dislocation density (shown in Figs. 5C and 5E). One can see primary (Mo,Ti)C precipitates and dislocation pile-ups formed at grain boundaries (GB). They could be due to the relaxation of residual stresses during annealing [22]. This SA heat treatment could be optimized to get rid of these precipitates and dislocations from the microstructure. This metallurgical state M1 (SA) allows studying the voids formation without lot of dislocations. Hence, this highlights the direct effect of Radiation Induced Precipitation (RIP) and permits to assess the effect of different elements in solid solution. For the record, in M2 (CW) metallurgical state, the solutes and the precipitates have an indirect role on swelling, stabilizing the dislocation network. In M1 (SA) this complexity in avoided. Comparing L50M1 (C: 15/15$\mathrm{Ti}$ ) and L47M1 (E: 15/25-Ti), the effect of nickel in solid solution is put forward.

To promote a thin titanium carbide precipitation along the dislocations, a heat treatment was carried out at $650{ }^{\circ} \mathrm{C}$ during $50 \mathrm{~h}$ on the M2 $(\mathrm{CW})$ material. This metallurgical state performed on L50 (15Cr-15Ni) is called M6 (Fig. 3B). This heat treatment was chosen based on different experiments reported in $[17,22,23]$. The nanometric coherent precipitates on L50M6 (Fig. 5B) are put in evidence in two beams conditions $(g=<200>)$ thanks to Moiré fringes perpendicular to $\mathrm{g}$. These are caused by a little misfit between the lattice parameter of the precipitates and the matrix. For Moiré fringes perpendicular to $\mathrm{g}$ active diffraction vector, the following equation can be considered, $D=d_{1} d_{2} /\left(d_{2}-d_{1}\right)$ [24]. This relates the spacing of fringes $D$, to interplanar spacing of the matrix and the precipitate $d_{1}$ and $d_{2}$, for a given diffraction vector. Considering measured value of $D=1.03 \mathrm{~nm}$ and $d_{1}=0.18 \mathrm{~nm}$ with $g=\left\langle 200>\right.$, the calculated value of $d_{2}=0.218 \mathrm{~nm}$ is close to the reticular distance of $\{200\}$ planes in the $(\mathrm{Ti}, \mathrm{Mo}) \mathrm{C}$ precipitates $\left(d_{200}=0.216 \mathrm{~nm}\right)$ [12]. A chemical analysis should be done to confirm their nature. One can see this fine precipitation of $(\mathrm{Ti}, \mathrm{Mo}) \mathrm{C}$ which nucleates on dislocations (Fig. 5B). SANS analysis was performed on a 


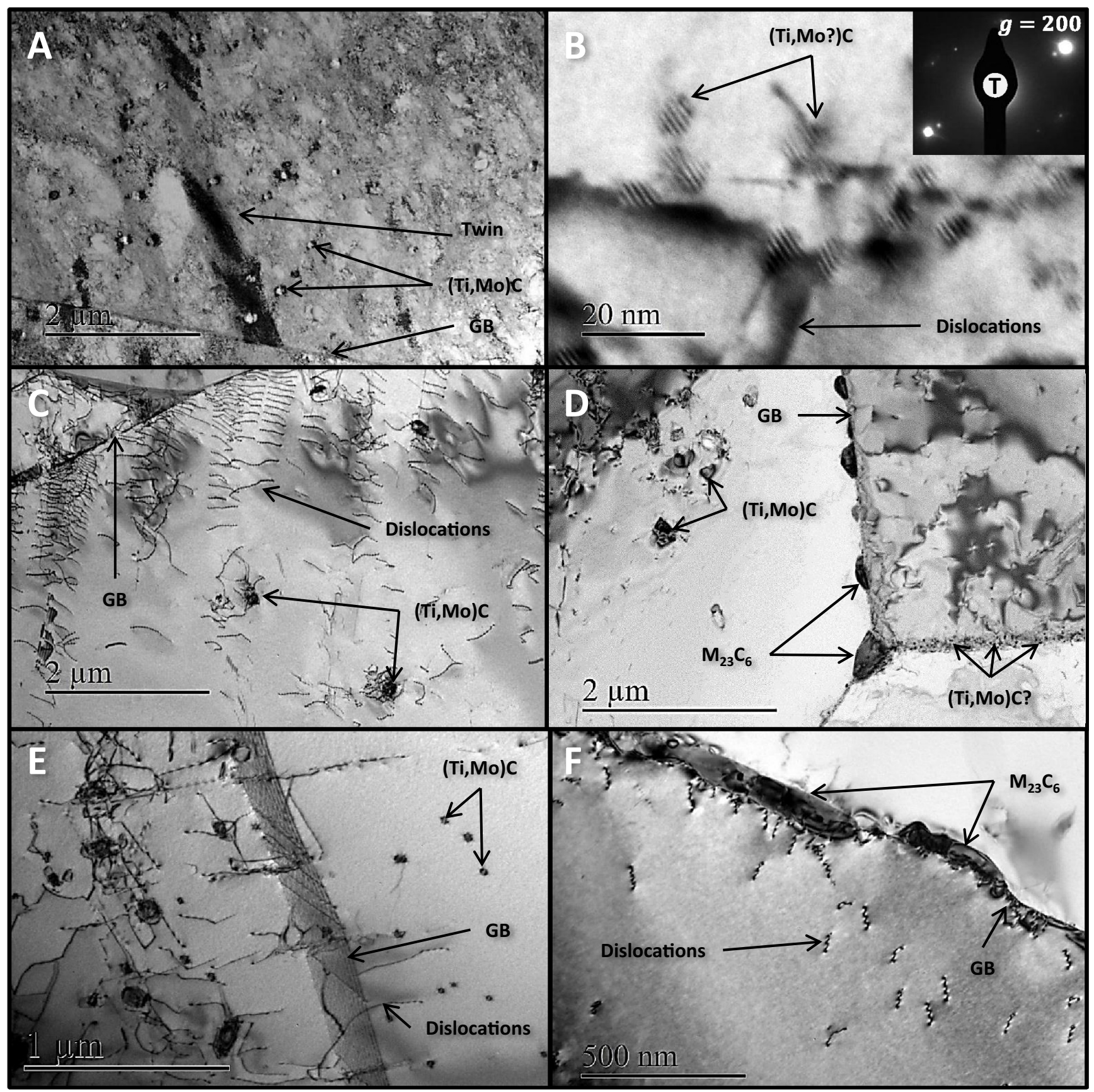

Fig. 5. BFTEM observations before irradiation: (A) L50M2 (15/15-Ti CW), (B) L50M6 (15/15-Ti CW+650 $\left.{ }^{\circ} \mathrm{C} / 50 \mathrm{~h}\right),(\mathrm{C}) \mathrm{L} 50 \mathrm{M} 1$ (15/15-Ti SA), (D) L50M3' (15/15-Ti SA+800 $\left.{ }^{\circ} \mathrm{C} / 24 \mathrm{~h}\right)$, (E) L47M1 (15/25-Ti SA), (F) L47M3' $\left(15 / 25-\mathrm{Ti} \mathrm{SA}+800{ }^{\circ} \mathrm{C} / 24 \mathrm{~h}\right)$.

bulk sample. A density $N_{\mathrm{p}}=5.9 \times 10^{22} \mathrm{~m}^{-3}$ and an average radius of $2 \mathrm{~nm}$ were measured. Hence the volume fraction of nanoprecipitation can be deduced: $f_{\mathrm{v}}=0.20 \%$. A TEM analysis on this sample provides a slightly higher mean radius $(2.4 \mathrm{~nm})$ with a lower density $\left(2.9 \times 10^{22}\right)$, resulting a volume fraction of $0.21 \%$. The smaller defects cannot be seen with TEM, which explains the slight difference with SANS technique. The amount of remaining Ti in solid solution cannot be estimated with WDS because the analysed volume is about $1 \mu \mathrm{m}^{3}$ and necessarily contains nanocarbides. The WDS results suggest that 0.2 wt.\% Ti was available in the solid solution before the $650{ }^{\circ} \mathrm{C}$ aging. A volume fraction of $0.20 \%$ (Ti,Mo)C measured with SANS corresponds to the precipitation of $0.11 \mathrm{wt} . \%$ of Ti. In consequence, the remaining Ti in solid solution could be about $0.09 \mathrm{wt} . \%$ in the metallurgical state M6. Hence, M6 allows to limit the effects of solutes and RIP on swelling and enlighten the nano-precipitates role. 


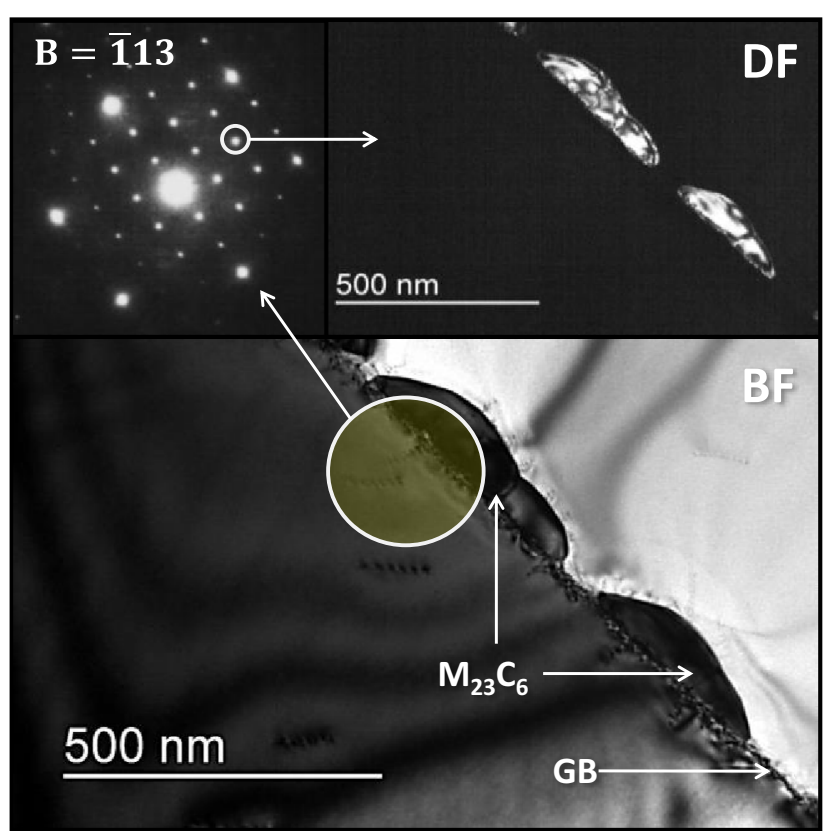

Fig. 6. BFTEM (BF) image of $\mathrm{M}_{23} \mathrm{C}_{6}$ precipitates at L47M3' (D) GB, with a micro-diffraction pattern on the precipitates and its corresponding Dark-Field (DF).

This role can be indirect by favouring the pinning of the dislocations, or direct by enhancing a recombination of Frenkel pairs (FP) or nucleation of cavities [13,25].

The $\mathrm{M} 3^{\prime}$ metallurgical state consists in a $24 \mathrm{~h}$ ageing at $800{ }^{\circ} \mathrm{C}$ after $\mathrm{SA}$ in order to precipitate all solutes. This ageing was chosen based on selective dissolution experiments and TTP diagram $[22,23]$ on 1.4970 steel. The microstructures of L50M3' (Fig. 5D and Fig. 6) and L47M3' (Fig. 5F), observed with TEM, reveal a coarse precipitation at GB. The EDX analysis on this precipitates extracted on replicas gives a mean composition of $73 \% \mathrm{Cr}$, $23 \% \mathrm{Fe}$ in $\mathrm{L} 50 \mathrm{M} 3^{\prime}$, and $60 \% \mathrm{Cr}, 20 \% \mathrm{Fe}, 6 \% \mathrm{Mo}$ in L47M3'. These carbides are enriched in chromium and could be $\mathrm{M}_{23} \mathrm{C}_{6}$ precipitates in agreement with the literature $[17,26]$. This characterisation is confirmed with micro-diffraction analysis shown in Figure 6. The precipitate diffraction spots were identified with Dark Field Images (DF). These reveal an epitaxy relationship between the precipitate and the matrix in one side of the GB. Hence the precipitate lattice parameter is measured to $1.07 \mathrm{~nm}$, which is very close to $\mathrm{M}_{23} \mathrm{C}_{6}$ lattice parameter. In addition, a dense $10-20 \mathrm{~nm}$ precipitation is observed along GB in both L47M3' and L50M3' (D and F). They are probably titanium carbides but this needs to be confirmed. TEM analysis indicates the absence of nano- $\mathrm{TiC}$ in intragranular position. The metallurgical state $\mathrm{M} 3{ }^{\prime}\left(800^{\circ} \mathrm{C} / 24 \mathrm{~h}\right)$ was chosen to get rid of RIP and solutes effects on swelling. It can be considered that the major part of solutes, in particular titanium, has precipitated. Comparing L50M3' and L47M3', the direct role of the matrix enriched in nickel can be investigated. Moreover, the importance of elements in solid solution during irradiation can be assessed by comparison of the $\mathrm{M} 3^{\prime}\left(\mathrm{SA}+800{ }^{\circ} \mathrm{C} / 24 \mathrm{~h}\right)$ with the M1 (SA) sample.

\section{Irradiation experiment}

\subsection{Irradiation conditions}

In order to simulate partially the neutron damage generated in a nuclear reactor, the irradiations were carried out with heavy ions. The motivations for using ions are numerous [27]. Mainly, the damage rate is about $10^{4}$ more important which makes possible to simulate a 10 years neutron irradiations in a few hours. Moreover, the samples are not activated and thus the characterisation is easy to perform. Hence, ion irradiation enables to test easily a wide range of samples and conditions, which are precisely what is required for investigations of the basic damage processes. However, the very high dose rate can bias the defects formation mechanisms and, in particular, change the incubation dose. Besides, ions create a damage only located close to the surface which makes difficult mechanical characterisations. Moreover, the surface is a sink for mobile defects and thus can also bias the swelling mechanisms. In this study, all the irradiated samples were observed near the surface. Even if this surface affects the swelling behaviour, it is considered as similar in all the samples and therefore we will focus comparison between the samples. Usually it is considered that irradiation with ions does not give any information about the incubation dose. Nevertheless it is believed that the trends comparing several alloys are the same with ion and neutron irradiations $[28,29]$.

In order to differentiate as much as possible these microstructures regarding the swelling behaviour, the highest damage is produced. The irradiation conditions were determined in consequence, based on experience [30] and SRIM calculations. The samples were irradiated at $600{ }^{\circ} \mathrm{C}$ with $2 \mathrm{MeV} \mathrm{Fe}^{2+}$ ions in JANNUS facility in CEA Saclay. This irradiation uses a rastered beam with a frequency of $500 \mathrm{~Hz}$. The experiment lasted $21 \mathrm{~h}$ divided in 4 days, under a very high ions flux of $4.22 \times 10^{12} \mathrm{~cm}^{-2} \mathrm{~s}^{-1}$ in average. Every day, the samples were heated the morning and cooled down at the end of the day. This operation spent less than 15 min.

The choice of the irradiation temperature is a key point in swelling behaviour. The formation of irradiation defects such as Frank loops, RIP or cavities, is the result of FP's creation caused by collisions and their subsequent thermal diffusion. The maximum swelling is between $500{ }^{\circ} \mathrm{C}$ and $550{ }^{\circ} \mathrm{C}$ with neutrons $[30,31]$. Since the dose rate caused by ions is $10^{4}$ higher than that of neutrons, there is less time for diffusion between two displacement events. Increasing the temperature accelerates the diffusion of point defects and allows time for microstructure evolution processes to take place. Mansur proposed a relationship to derive the temperature shift, at fixed doses, to obtain a similar swelling [16]. This is deduced keeping the net flux of vacancies over interstitials to a particular type of sink (cavities) to be invariant. For the damage rate generated in this experiment $\left(2.4 \times 10^{-3} \mathrm{dpa} \mathrm{s}^{-1}\right)$, the model gives a temperature around $600{ }^{\circ} \mathrm{C}$ corresponding to the swelling peak. This result is in good accordance with few experimental results $[32,33]$ realised with $2 \mathrm{MeV}$ ions on steels containing 0.2 wt. $\%$ of Ti. Hence $600{ }^{\circ} \mathrm{C}$ was chosen 


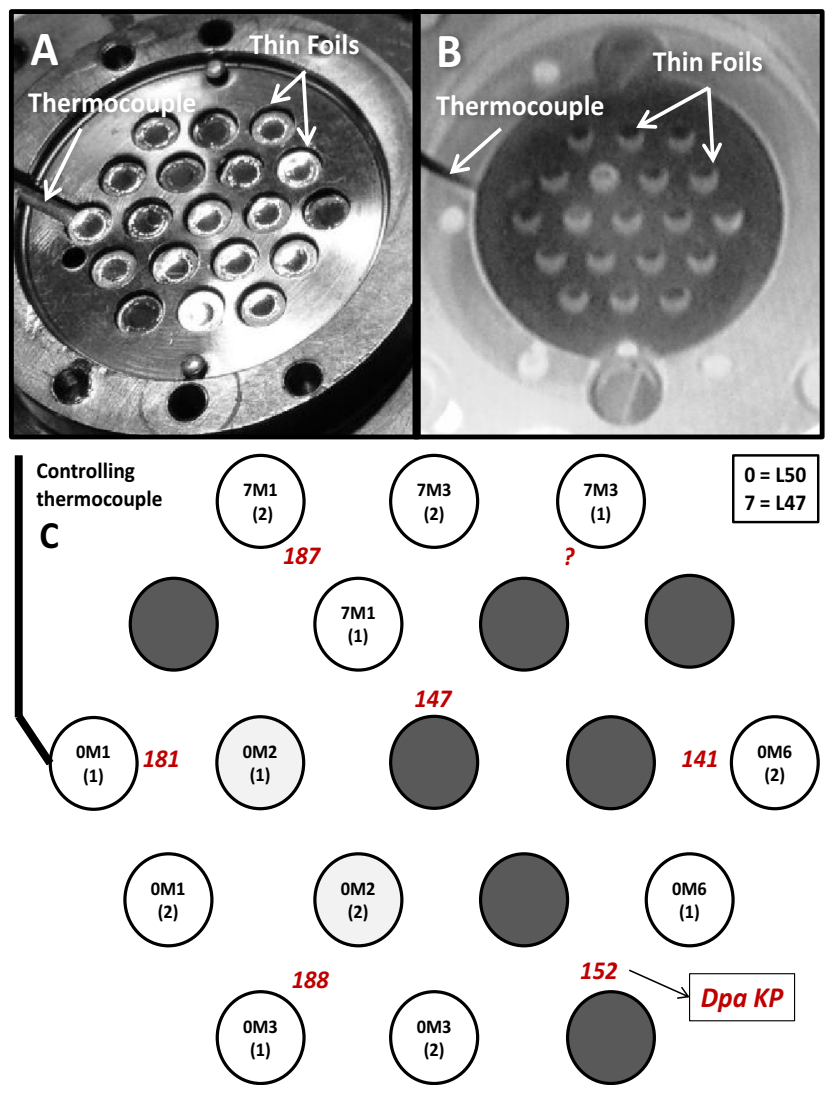

Fig. 7. Sample holder, optical photography after (A) and during (B) irradiation, holder sketch (C).

as irradiation temperature. Nevertheless, even at this temperature, the kinetics of evolution of defects is not increased by a factor $10^{4}$ as the dose rate, and this can bias the swelling mechanisms. Also, some experiments with $5 \mathrm{MeV}$ ions irradiation on $\mathrm{Fe}-\mathrm{Cr}-\mathrm{Ni}$ alloys indicate that the maximum swelling should be produced close to $675{ }^{\circ} \mathrm{C}$ on ternary alloys $[34,35]$. Indeed the temperature of the maximum swelling is reduced with the addition of titanium [25] due to a mechanism described by Venker and Ehrlich [36]. This effect is less important but also observed by Seran et al. under neutron irradiation on 316Ti SA [15].

\subsection{Experiments}

Samples are $3 \mathrm{~mm}$ diameter TEM foils, about $50 \mu \mathrm{m}$ thick and electro polished only on one face. After being irradiated, this face is protected with Lacomite and the other face is polished until a hole is formed. Then, a $100 \mathrm{~nm}$ thick thin-foil can be observed by TEM. A picture of oneface polished samples set in the holder after irradiation is given in Figure 7A. To be sure of the reproducibility and reliability of the results, the 6 samples were doubled: (1) and (2). Their respective position in the holder is represented on the sketch of Figure 7 .

During the experiments, the control of the temperature is sensitive. Samples are heated by a heating plate stuck behind the holder but also by the ion beam. The control of the irradiation temperature was ensured at $600{ }^{\circ} \mathrm{C}$ by a

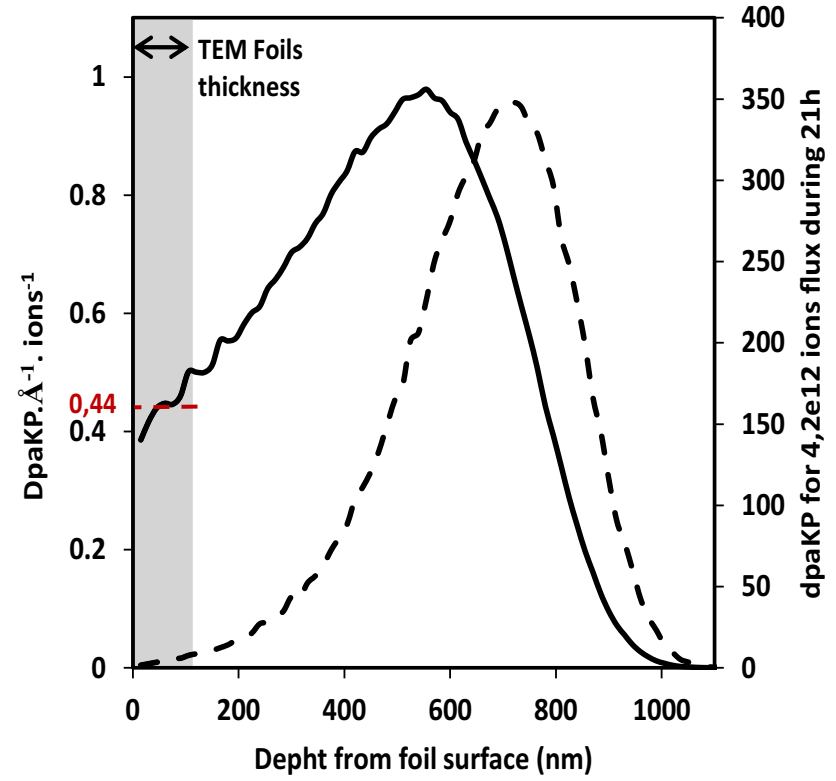

Fig. 8. Damage profile computed with SRIM (full line) and $\mathrm{Fe}^{2+}$ implantation (dotted line).

thermocouple in contact with a steel chock under the thin foil L50M1(1). It was supplemented by a thermal camera. In order to avoid an overheating of the samples, the thermal emissivity was calibrated at $550{ }^{\circ} \mathrm{C}$ with the beam turned off. During irradiation, while the thermocouple set the chock temperature at $600{ }^{\circ} \mathrm{C}$, the thermal camera indicated a temperature of about $625{ }^{\circ} \mathrm{C}$ for each foil. This gap can be due to an overheating caused by the beam, or to a calibration drift as a function of temperature (the emissivity calibration was performed at $550{ }^{\circ} \mathrm{C}$ ). Moreover, according to the thermal camera (photo Fig. 7B), the foils L47M1(1) and L50M2(1) probably overheated of $50{ }^{\circ} \mathrm{C}$. A bad contact between the foils and the steel chocks under them is suspected.

\subsection{Dose calculation}

Considering a flux of $2 \mathrm{MeV}$ iron ions, the damage (full line) in dpa and the ions implantation profiles (dotted line) were computed with the SRIM software and are given in Figure 8. The model used is that of Kinchin and Pease (KP) with the parameters recommended by Stoller and Toloczko [37]. It gives a dpa KP value close to the dpa NRT used for neutron damage. The displacement threshold energy used is $40 \mathrm{eV}$ (Stoller specification) instead of $18 \mathrm{eV}$ (measured threshold energy) [28] and the lattice and surface binding energy is set to 0 . The dpa KP can be calculated by the following formula:

$$
\operatorname{dpa~KP}=\frac{x \varphi t M}{\rho N_{a}}
$$

where $x$ is the dpa per ions per angstrom computed with SRIM, $\varphi$ is the ions flux, $t$ is the time, $M$ is the sample molar mass, $\rho$ its density and $N_{a}$ the Avogadro number. 


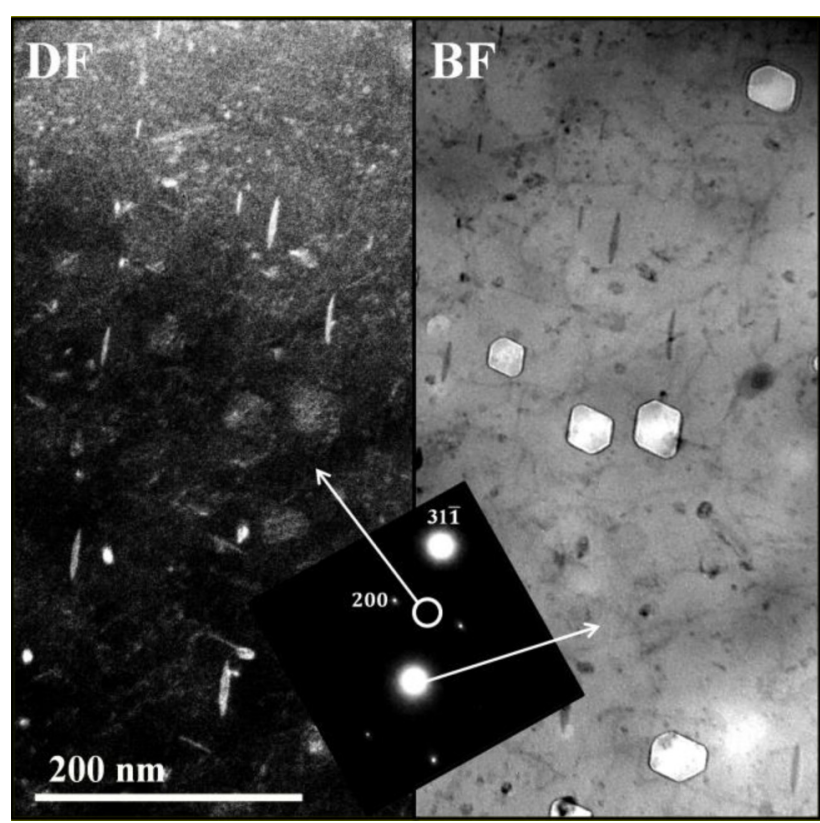

Fig. 9. BFTEM and DFTEM micrographs of Frank loops in L50M3' (D) after irradiation.

With the experimental procedure used, the TEM observations are performed on the first $100 \mathrm{~nm}$ from the surface where the incident ions are not implanted. Since there is a dose gradient in the thickness of the thin foil, an average value of $x=0.44 \mathrm{dpa} / \mathrm{A} /$ ion is considered.

The ion flux $\varphi$ was measured by seven Faraday cages at different places over the samples holder. Using equation (1), the corresponding dose (dpa KP) was calculated and indicated on the holder shown in Figure 7 . The dose repartition is not very homogeneous and can vary up to 30 dpa between different samples. Nevertheless, considering the large gradient of dpa through the TEM thin foil, this variation is limited. In average, the dpa rate is about $2.4 \times 10^{-3} \mathrm{dpa} \mathrm{s}^{-1}$.

\section{Results}

\subsection{Results}

The results show a good reproducibility because no significant differences have been noticed between the foils (1) and (2) with the same microstructure. Besides, a good homogeneity of the damage was noticed inside a given sample. A bright field TEM image is given in Figure 10 for each sample after irradiation. All micrographs were taken close to $B=\langle 110\rangle$ zone axis, in two-beams condition $(g=<200>)$, except Figures 10D and 10F which were taken still close to $B=\langle 110\rangle$ zone axis but out of contrast in order to better see cavities. They were chosen as representative as possible of the microstructure. For an easy comparison, the samples microstructures in Figure 10 are arranged in same order as in Figures 3 and 5 (samples before irradiation).

In all the samples, irradiation defects are observable such as Frank loops, precipitates and sometimes cavities. Two kinds of precipitates are distinguished. P1 type precipitates are pointed out with red arrows in Figure 10 micrographs. They show moiré fringes perpendicular to $g=\langle 200\rangle$ direction and $D$ spacing $(1.1 \mathrm{~nm}<D<1.4 \mathrm{~nm})$. Consequently, they are supposed to be coherent nano $(\mathrm{Mo}, \mathrm{Ti}) \mathrm{C}$, even if $D$ value is slightly higher than the theoretical value $D_{\mathrm{th}}=1.05 \mathrm{~nm}$. P2 type precipitates are pointed out with yellow arrows in Figure 10. Micro-diffractions indicate that most of them could be $\mathrm{M}_{23} \mathrm{C}_{6}, \mathrm{M}_{6} \mathrm{C}$ or G-phase precipitates. Frank loops were highlighted with a DF on their stacking fault, close to $B=\langle 110>$ with $g=<3 \overline{1} 1>$ (rel-rod technique). An example is given in Figure 9. Finally cavities appear with a black contour when the beam is under-focused and with a bright one when the beam is over-focused. In the following, all the cavity images are shown under-focused.

Three kinds of defect have been quantified and reported in Table 3: P1 precipitates, Frank loops and cavities. Very close to the sample hole, where the foil is very thin, much less or no defects are detectable. This is probably because the surface acts as an efficient sink for defects. As a consequence, the samples were characterised far enough from the hole where the thickness is about $100 \mathrm{~nm}$. Yet, this thickness was not measured but estimated between $80 \mathrm{~nm}$ and $120 \mathrm{~nm}$. This involves an uncertainty $( \pm 50 \%)$ on the defects density, the swelling and the volume fraction.

The samples L50M2, L50M1 and L47M1 given in Figures 10A, 10C and 10E, do not show any sign of swelling. There is no cavity but an important density of P2 (yellow arrows) and P1 (red arrows) type precipitates, which were not present before irradiation. P2 type precipitates are particularly numerous in the high nickel sample L47M1 (E). The samples L50M6, L50M $3^{\prime}$ and L47M3' given in Figures 10B, 10D and 10F show cavities. Therefore these 3 alloys are probably less resistant to swelling at this temperature. Cavities are preferentially faceted with $\{111\}$ close-packed planes, as mentioned in the literature [2]. This observation is particularly noticeable on L50M3' sample (Fig. 10D). L50M3' present the largest cavities which can reach $200 \mathrm{~nm}$ diameters. Nevertheless, the samples show heterogeneities probably due to segregations (Fig. 2). Sides of the thin foil show cavities preferentially concentrated at GB but other sides show homogenous dispersion (Fig. 10D) where the swelling was roughly $2.8 \%$. The voids in L47M3' (F) are homogenously dispersed and generate $0.38 \%$ swelling. Two populations are apparent: a very dense set of cavities with a few nanometers size and some bigger ones of about $22 \mathrm{~nm}$ which are generally linked to dislocations. Finally the sample L50M6 (9B) has scarce cavities with different sizes up to $80 \mathrm{~nm}$. They are only present in some places, often next to GB, large precipitates or between twins. On can notice in Figure 10D, an association of a cavity with a $\mathrm{P} 2$ precipitate but this phenomenon was very rare in all the samples. Under neutron irradiation cavities are often associated with G-phases or $\mathrm{M}_{6} \mathrm{C}$ precipitates $[7,12,16,17,38]$. Most of the time cavities were linked to the dislocation network as one can easily observe in Figure 10B. In such cases, dislocations are easy diffusion paths for point defects (interstitials or vacancies). 


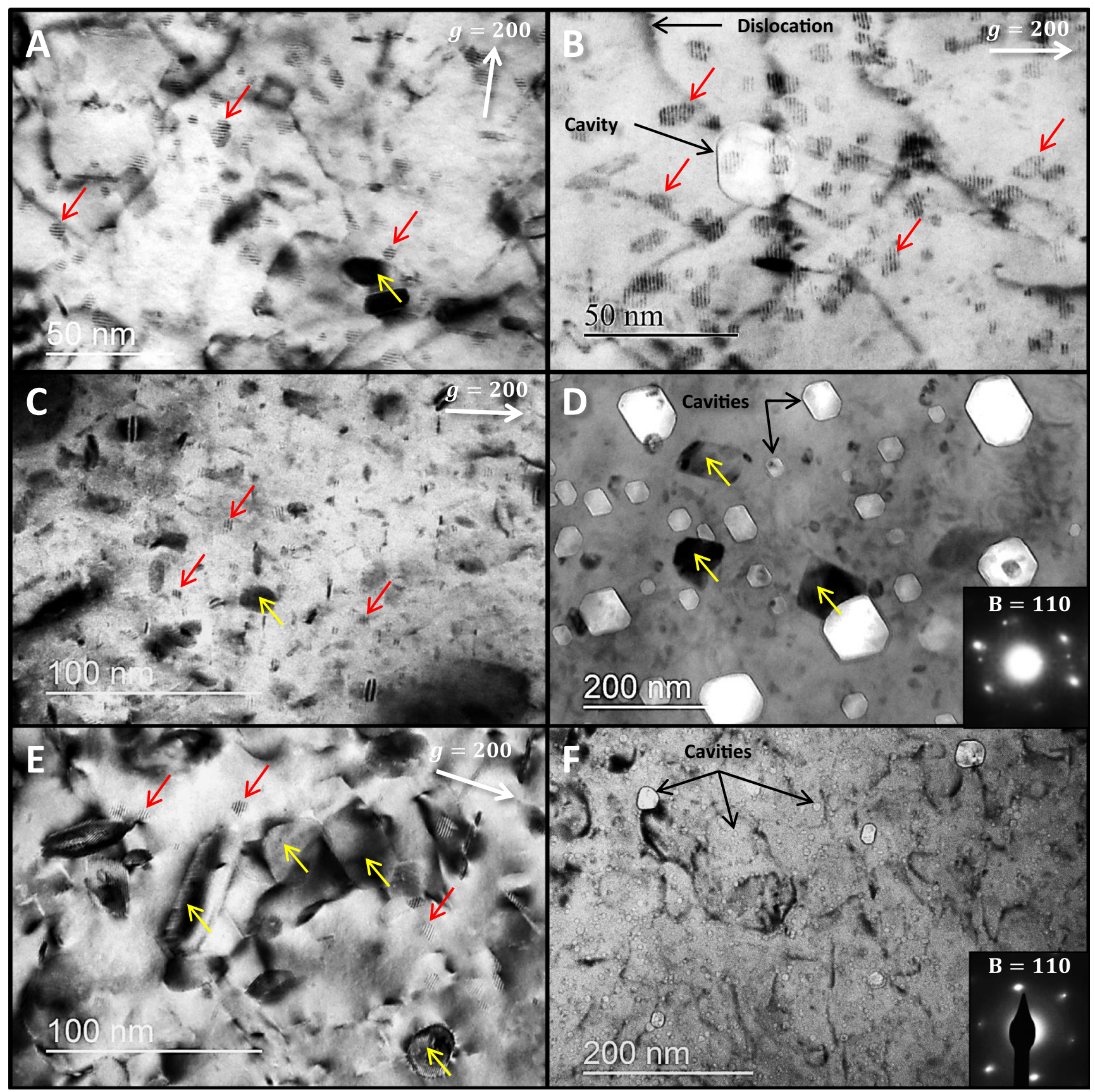

Fig. 10. BFTEM observations after irradiation: (A) L50M2 (15/15Ti CW), (B) L50M6 (15/15Ti CW+650 $\left.{ }^{\circ} \mathrm{C} / 50 \mathrm{~h}\right)$, $(\mathrm{C}) \mathrm{L} 50 \mathrm{M} 1$ $(15 / 15 \mathrm{Ti} \mathrm{SA}), \mathrm{D}) \mathrm{L}_{0 \mathrm{M} 3}{ }^{\prime}\left(15 / 15 \mathrm{Ti} \mathrm{SA}+800{ }^{\circ} \mathrm{C} / 24 \mathrm{~h}\right) 2 \mu \mathrm{m}$ far from GB, (E) L47M1 (15/25Ti SA), (F) L47M3' (15/25Ti SA $+800{ }^{\circ} \mathrm{C} / 24 \mathrm{~h}$ ).

Concerning P1 type precipitates, their density (and volume fraction) in M1 state (solution annealed sample) is lower. This could be explained by the lack of dislocations, and as a consequence, a lack of nucleation sites. Nevertheless, this explanation does not apply for the $\mathrm{M}^{\prime} \quad\left(\mathrm{SA}+800{ }^{\circ} \mathrm{C} / 24 \mathrm{~h}\right)$ samples, with low dislocations density but with a high density of $\mathrm{P} 1$ precipitates, especially L47M3'. In L50M6 sample (B) the P1 precipitation which were already present before irradiation (Fig. 5B), increased during the irradiation from $0.21 \%$ to $0.46 \%$ (TEM analysis).
Finally regarding Frank loops, their density in L47M3' is ten times lower than in the other samples. This can be explained by the increase of SFE with nickel content. Frank loops which create a stacking fault would nucleate with more difficulties in L47 grade $[19,20]$.

\subsection{Discussion}

In all the samples the swelling almost never go over $1 \%$. This indicates that irradiation was probably not conducted at the swelling peak for each material. It is known to depend 
Table 3. TEM quantification of three kind of irradiation defects: type P1 of precipitates, frank loops and cavities.

\begin{tabular}{|c|c|c|c|c|c|c|c|c|c|c|}
\hline \multicolumn{3}{|c|}{ Sample } & \multicolumn{3}{|c|}{ Precipitates P1 type (red arrow) } & \multicolumn{2}{|c|}{ Franck loops } & \multicolumn{3}{|c|}{ Cavities } \\
\hline Grade & State & Place & $\begin{array}{l}\text { Size } \\
(\mathrm{nm})\end{array}$ & $\begin{array}{l}\text { Density } \\
\left(10^{21} \mathrm{~m}^{-3}\right)\end{array}$ & $f_{\mathrm{v}}(\%)$ & $\begin{array}{l}\text { Size } \\
(\mathrm{nm})\end{array}$ & $\begin{array}{l}\text { Density } \\
\left(10^{21} \mathrm{~m}^{-3}\right)\end{array}$ & $\begin{array}{l}\text { Size } \\
(\mathrm{nm})\end{array}$ & $\begin{array}{l}\text { Density } \\
\left(10^{21} \mathrm{~m}^{-3}\right)\end{array}$ & $\begin{array}{l}\text { Swelling } \\
(\%)\end{array}$ \\
\hline L50 & M2: CW & A & 4.5 & 48 & 0.30 & 18 & 2.1 & / & 0 & 0 \\
\hline L50 & M6: $650{ }^{\circ} \mathrm{C} / 50 \mathrm{~h}$ & B & 4.8 & 48 & 0.43 & 25 & 1.4 & 19 & 0.02 & 0.01 \\
\hline L50 & M1: SA & $\mathrm{C}$ & 4.4 & 11 & 0.06 & 21 & 1.9 & / & 0 & 0 \\
\hline L50 & $\mathrm{M}^{\prime}: 800{ }^{\circ} \mathrm{C} / 24 \mathrm{~h}$ & $\mathrm{D}$ & 4.9 & 27 & 0.22 & 22 & 2.6 & 36 & 0.55 & $2.8^{*}$ \\
\hline L47 & M1: SA & $\mathrm{E}$ & 5.4 & 5 & 0.06 & 22 & 2.4 & / & 0 & 0 \\
\hline L47 & $\mathrm{M3}^{\prime}: 800{ }^{\circ} \mathrm{C} / 24 \mathrm{~h}$ & $\mathrm{~F}$ & 3.6 & 61 & 0.17 & 23 & 0.16 & $22+4.5$ & $0.2+40$ & $0.16+0.22$ \\
\hline
\end{tabular}

Experimental error estimation: $\pm 50 \%$ for the density, $f_{\mathrm{v}}$ and swelling measurements; $\pm 10 \%$ for the size measurement.

on the vacancy mobility which is affected by the solutes content of each alloy (Venker's mechanism) [36]. Nevertheless, the results allow observing different phenomena.

\subsubsection{Effect of titanium in solid solution}

All the samples without cavities after irradiation (L50M1, L47M1 and L50M2) have $0.2 \% \mathrm{Ti}$ in solid solution before irradiation. Cavities are visible only on pre-aged microstructures: M3' (D and E) and M6 (B) samples. Consequently these alloys had less solutes and especially titanium in solid solution than M1 (SA) and M2 (CW) samples. This confirms the major role played by titanium in solid solution to limit the swelling. The creation of solute-vacancy complexes (s-v) can act as recombination sites for vacancies and interstitials $[2,12,39,40]$. When the recombination processes are enhanced, the vacancy supersaturation decreases. Hence the swelling is reduced. According to the literature these complexes are formed more easily with solutes having a bonding energy with vacancies greater than $0.2-0.3 \mathrm{eV}$. For titanium, $E_{\mathrm{v}-\mathrm{Ti}}=$ $0.3 \mathrm{eV}$ [13]. Results of numerical methods by Mansur show that with increasing values of binding energy, the void nucleation decreases [40]. Finally, David et al. show that the increase of titanium in solid solution reduces the temperature of the swelling peak [25]. One can explain this behaviour by the increase of vacancy mobility with the titanium content (Venker's mechanism) [36]. It will be very interesting to perform irradiations at lower temperatures to check if some swelling can be observed in SA and cold worked samples with lot of titanium in solid solution (A, C and E samples).

\subsubsection{Effect of nickel in solid solution}

L50M3' (D) and L47M3' (F) samples followed the same thermal cycle. They were both SA and aged at $800{ }^{\circ} \mathrm{C}$ during $24 \mathrm{~h}$ before irradiation to force a coarse precipitation and remove solutes from the matrix. They have probably comparable amounts of titanium in solid solution. Therefore, the difference between the two samples before irradiation is the amount of $\mathrm{Ni}$ in the matrix. Unlike titanium, the swelling temperature does not vary too much with nickel content under ions irradiation [35]. Ni is known to increase the incubation dose for swelling [11,25,35,41,42]. In our experiment, $\mathrm{Ni}$ decreases the cavities mean size but increases their density. This density increase is due to the presence of a population of a nano-cavities in L47M3' $(\mathrm{F})$, which are absent from L50M3' (D). The high Ni-v binding energy $\left(E_{\mathrm{v}-\mathrm{Ni}}=0.26 \mathrm{eV}\right)$ could contribute to the formation of $\mathrm{Ni}-\mathrm{v}$ clusters. Hence, these complexes would decrease vacancies mobility, act as recombination sites for punctual defects or as nucleation sites for cavities. The assumption based on the trapping theory proposed by Mansur is consistent with the TEM micrographs: there is a higher cavities density but a decrease of the swelling, when the nickel content increases from $15 \%$ to $25 \%$. Nevertheless these results contradict previous experimentations on $\mathrm{Fe}-15 \mathrm{Cr}-\mathrm{XNi}$ ternary alloys summarized by Muroga et al. [43]. In these works, the sharp swelling drop with nickel up to $35 \% \mathrm{Ni}$ is explained by a drop of voids density. Garner claims that this density reduction is caused by an increase of vacancy mobility with nickel [35]. However, this increase has been measured only by comparing $X=20 \%$ with $X=45 \% \mathrm{Fe}-15 \mathrm{Cr}-\mathrm{XNi}$ ternary alloys. In the nickel chemical content range of this experiment (from 15\% to $25 \%$ of nickel) the vacancy mobility decreases according to Venker and Ehrlich [36].

One can also notice the higher density of Frank loops in the L50M3' than in L47M3'. Frank loops are very biased sinks [44]. They could increase the vacancy supersaturation and therefore the swelling in L50M3' (D) compared to L47M3' (F).

The literature $[28,39,41,43,45,46]$ discusses also the dependence of sinks strength on nickel contents. By RIS mechanisms, nickel is known to segregate around sinks and reduce the dislocation bias. An enriched-nickel coating around cavities strongly increases their biases against interstitials and enhances swelling [46]. The RIS mechanisms decrease with nickel content in the alloy [42].

\subsubsection{Effect of sinks density}

L50M6 (B) and L50M3' (D) were both titanium depleted before irradiation but L50M6 contains much less cavities than L50M3'. This may be attributed to the presence of a fine precipitation combined with a dense dislocations network in L50M6. The nano-titanium carbides stabilised 
the dislocations which are sinks for vacancies and interstitials. The supersaturation of vacancies is decreased and consequently the void nucleation is decreased as well $[4,6,7]$.

\section{Conclusions}

The formation of cavities under $2 \mathrm{MeV}$ Fe ion irradiation at $600{ }^{\circ} \mathrm{C}$ in different microstructures of a $15 \mathrm{Cr}-15 \mathrm{Ni}$ and a $15 \mathrm{Cr}-25 \mathrm{Ni}$, stabilized with titanium, was investigated.

- In this irradiation condition, solutes and especially titanium in solid solution suppress void formation.

- Increasing the nickel concentration from $15 \%$ to $25 \%$ decreases swelling. Nickel increases the number of cavity but reduces their size in this experiment.

- The combination of a nano-precipitation with a dense dislocation network decreases the number of cavities.

Additional irradiations at lower temperatures, to obtain full swelling-temperature curves for each material, will be necessary to complete the analysis.

The authors would like to thank warmly Nico Wispealare from OCAS Gent for the elaboration of the model steels; Joel Malaplate for his help in the design of the experiment; Yves Serruys and all the JANNUS-Saclay team.

\section{Nomenclature}

$x \quad$ dpa per ions

$\varphi \quad$ ions flux in $\mathrm{cm}^{-2} \mathrm{~s}^{-1}$

$t \quad$ time in $\mathrm{s}$

$M \quad$ molar masse in $\mathrm{kg} \mathrm{mol}^{-1}$

$\rho \quad$ density in $\mathrm{kg} \mathrm{m}^{-3}$

$N_{a} \quad$ Avogadro number

$E_{\mathrm{v}-\alpha} \quad$ vacancy $-\alpha$ bond energy

\section{References}

1. C. Cawthorne, J.E. Fulton, Nature 216, 515 (1967)

2. G.S. Was, Fundamentals of Radiation Materials Science (Springer, 2007), Chap. 8

3. P. Dubuisson, Core Structural Materials - feedback experience from Phénix Design Manufacturing and Irradiation behaviour of Fast Reactor Fuel, IAEA-TECDOC - CD 1689, pp. 235-247, 2013

4. A. Renault et al., Correlation of radiation-induced changes in microstructure/microchemistry, density and thermos-electric power of type 304L and 316 stainless steels irradiated in the Phénix reactor, J. Nucl. Mater. 460, 72 (2015)

5. M. Le Flem, P. Gavoille, Advanced steel claddings for SFRS: feedback and challenges, in Final workshop GETMAT, 2013 (2013)

6. E. Wakai, N. Hashimoto, Swelling of cold worked austenitic stainless steels irradiated in HFIR under spectrally tailored conditions, J. Nucl. Mater. 307, 352 (2002)

7. S. Hamada, M. Suzuki, Microstructural evolution in austenitic stainless steels irradiated to $57 \mathrm{dpa}$ in HFIR, J. Nucl. Mater. 179, 515 (1991)
8. P. Dubuisson, A. Maillard, C. Delalande et al., The effect of phosphorus on the radiation induced microstructure of stabilized austenitic stainless steels, in 15th International Symposium on the Effects of Radiation on Materials, Nashville (1990)

9. E. Lee, L. Mansur, Fe-15Ni-13Cr austenitic stainless steels for fission and fusion reactor applications. III. Phase stability during heavy ion irradiation, J. Nucl. Mater. 278, 20 (2000)

10. P. Mazias, Overview of microstructural evolution in neutronirradiated austenitic stainless steels, J. Nucl. Mater. 205, 118 (1993)

11. J.L. Seran et al., Behaviour under neutron irradiation of the 15-15Ti and EM10 steels used as standard materials of the Phénix fuel subassembly, Effects of radiation on materials, in 15th International Symposium ASTM STP 1125, Philadelphia (1992), p. 1209

12. I. Neklyudov, V. Voyevodin, Radiation swelling of modified austenitic steels, Russ. Phys. J. 51, 400 (2008)

13. V. Voyevodin, I. Neklyudov, Microstructural evolution and radiation stability of steels and alloys, J. Nucl. Mater. 271, 290 (1999)

14. B. Raj, M. Vijayalakshmi, Radiation Damage of Structural Materials for Fast Reactor Fuel Assembly (ICTP\&IAEA, Trieste, 2009)

15. J. Seran, L. Le Naour, P. Grosjean et al., Swelling of microstructure of neutron irradiated titanium modified type 316 stainless steel, in Effect of Radiation on Materials, 12th Int. Symp., Philadelphia, USA (1985), p. 233

16. L. Mansur, Theory and experimental background on dimensional changes in irradiated alloys, J. Nucl. Mater. 216, 97 (1994)

17. C. Delalande, Influence du Phosphore sur le comportement hors et sous irradiation des aciers austénitiques multi stabilisés, Chapitre 3, PhD. Thesis, Paris, 1992

18. A. Padilha, R. Plaut, Annealing of cold-worked austenitic stainless steels, ISIJ Int. 43, 135 (2003)

19. S. Yang, J. Spruiell, Cold-worked state and annealing behavior of austenitic stainless steel, J. Mater. Sci. 17, 677 (1982)

20. R. Schramm, R. Reed, Stacking-fault energies of 7 commercial austenitic stainless-steels, J. Miner. Met. Mater. Soc. 7, 1345 (1975)

21. V. Voronin, E. Valiev et al., Neutron diffraction analysis of $\mathrm{Cr}-\mathrm{Ni}-\mathrm{Mo}-\mathrm{Ti}$ austenitic steel after cold plastic deformation and fast neutrons irradiation, J. Nucl. Mater. 459, 97 (2015)

22. M. Terada, R. Altobelli, Microstructure and intergranular corrosion of the austenitic stainless steel 1.4970, J. Nucl. Mater. 358, 40 (2006)

23. A. Padilha, G. Schanz, Ausscheidungsverhalten des titanstabilisierten austenitischen stahls $15 \%$ Q-15\% Ni-1\% Mo-TiB (DIN-werkstoff-nr. 1.4970), J. Nucl. Mater. 105, 77 (1982)

24. B. Fultz, J.M. Howe, Transmission Electron Microscopy and Diffractometry of Materials (Springer, Germany, 2002)

25. C. David et al., A study of the effect o titanium on the void swelling behaviour of D9 steels by ion beam simulation, J. Nucl. Mater. 383, 132 (2008)

26. J.S. Yang, Radiation-induced changes in microstructure, in 13th int. symp. ASTM STP 955 (1987), Vol. 1, p. 628

27. G.S. Was, R.S. Averback, Comprehensive Nuclear Materials, (Elsevier Ltd., 2012), Chapter 1.07

28. T. Allen, J. Cole, Swelling and radiation-induced segregation in austenitic alloys, J. Nucl. Mater. 342, 90 (2005) 
29. F.A. Garner et al., Use of self-ion bombardment to study void swelling in advanced radiation-resistant alloys, in 17th Int. Symp. Conf. on Environmental Degradation of Materials in Nuclear Power Systems, Ottawa, Canada (2015)

30. A. Courcelle et al., in SMINS Workshop, Idaho Falls, USA (2013)

31. T. Muroga, F. Garner, Microstructural investigation of swelling dependence on nickel content in fast neutronirradiated Fe-Cr-Ni austenitic ternaries, J. Nucl. Mater. 179-181, 546 (1991)

32. O. Borodin et al., Synergistic effects of helium and hydrogen on self-ion-induced swelling of austenitic $18 \mathrm{Cr} 10 \mathrm{NiT}$ i stainless steel, J. Nucl. Mater. 442, 817 (2013)

33. A. Kalchenko et al., Prediction of swelling of $18 \mathrm{Cr} 10 \mathrm{NiTi}$ austenitic steel over a wide range of displacement rates, J. Nucl. Mater. 399, 114 (2010)

34. F.A. Garner, Irradiation performance of cladding and structural steels in liquid metal reactors, in Materials Science and Technology (VCH Publishers, New York, 1994), Vol. 10A: Nuclear Materials, Chap. 6, Part I

35. F.A. Garner, Recent insights on the swelling and creep of irradiated austenitic alloys, J. Nucl. Mater. 123, 459 (1984)

36. H. Venker, K. Ehrlich, Relation between partial diffusion coefficients in alloys and their swelling behaviour under fast neutron irradiation, J. Nucl. Mater. 60, 347 (1976)
37. R. Stoller, M. Toloczko, On the use of SRIM for computing radiation damage exposure, Nucl. Instrum. Meth. Phys. Res. 310, 75 (2013)

38. F.A. Garner, in Comprehensive Nuclear Materials (Elsevier Ltd., USA, 2012), Chap. 4.02

39. F.A. Garner, W.G. Wolfer, The effect of solute additions on void nucleation, J. Nucl. Mater. 102, 143 (1981)

40. L.K. Mansur, H. Yoo, The effects of impurity trapping on irradiation-induced swelling and creep, J. Nucl. Mater. 74, 228 (1978)

41. T. Muroga, F. Garner, Microstructural investigation of swelling dependence on nickel content in fast neutron-irradiated Fe-Cr-Ni austenitic ternaries, J. Nucl. Mater. 179, 546 (1991)

42. J. Bates, R. Powell, Irradiation-induced swelling in commercial alloys, J. Nucl. Mater. 102, 200 (1981)

43. T. Muroga, F.A. Garner, J.M. McCarthy, Influence of nickel content on microstructures of $\mathrm{Fe}-\mathrm{Cr}-\mathrm{Ni}$ austenitic ternaries irradiated with fast neutrons or heavy ions, in Effect of Radiation on Materials, 15th Int. Symp., Philadelphia, USA (1992), p. 1015

44. W.G. Wolfer, L.K. Mansur, The capture efficiency of coated voids, J. Nucl. Mater. 91, 265 (1980)

45. J.J. Hoyt, F.A. Garner, The solute dependence of bias factors in Irradiated Fe-Ni alloys, J. Nucl. Mater. 179, 1096 (1991)

46. L. Mansur, W. Wolfer, Influence of a surface coating on void formation, J. Nucl. Mater. 70, 825 (1978)

Cite this article as: Baptiste Rouxel, Caroline Bisor, Yann De Carlan, Arnaud Courcelle, Alexandre Legris, Influence of the austenitic stainless steel microstructure on the void swelling under ion irradiation, EPJ Nuclear Sci. Technol. 2, 30 (2016) 